\title{
FORMAS DE EVALUACIÓN COMO ESTRATEGIAS DE CONTROL EN LA EDUCACIÓN SUPERIOR EN COLOMBIA*
}

\author{
Tomás Sánchez Amaya
}

\section{Perspectiva de la indagación}

Asistimos a una época histórica caracterizada por la disciplina y el control, o mejor, podríamos decir, a un tiempo en que transitamos diversos regímenes controlatorios, en los cuales la evaluación de múltiples modos hace presencia y funge como dispositivo de regulación, de disciplina, de sanción social, de inclusión, de exclusión; un mecanismo a través del cual a cada cosa, a cada institución, a cada sujeto, a cada saber, a cada proyecto... se le ubica en un lugar determinado y se le caracteriza, de unas formas preestablecidas.

Bien podríamos decir que en las sociedades modernas, la evaluación en virtud de su omnipresencia, se ha constituido en un acontecimiento relevante, por ser ese novedoso sistema que procura la vigilancia permanente de los individuos y de las colectividades, aquella maquinaria extendida por doquier, que somete a la población a una regulación instantánea; ese enjambrazón de dispositivos que serpentean por todas partes, que operan de diversas formas, que gobiernan, regulan, vigilan y controlan, no ya los individuos unitarios sino la multitud, induciéndola, como señaló Foucault, a "un estado consciente y permanente de visibilidad que garantiza el funcionamiento automático del poder" (1976, p. 204). O, podríamos decir a Gabriel García Márquez, la evaluación, a través de un conjunto casi infinito de formas, ciñe y constriñe nuestra existencia "de la cuna a la tumba", incluso más allá de estas, vigilándo lo todo, regulándolo todo, controlándo lo todo.

La perspectiva metodológica puesta en escena en esta indagación dice relación con la caja de herramientas foucaultiana constituida por la arqueología, la genealogía y la subjetividad, a partir de un triple análisis: de las modalidades enunciativas acerca de lo efectivamente dicho y escrito sobre la evaluación -en la educación superior; de las relaciones de poder que comportan sus prácticas; y de los sujetos que agencia.

Las sociedades modernas han entrado paulatinamente en la configuración de una cultura de la evaluación; asistimos, en efecto, a una época panevaluativa: todo se evalúa y en todo momento, mucho más, si la evaluación se refiere al ámbito educativo y de modo específico a los procesos de enseñanza y aprendizaje. En este contexto de perpetua y permanente valoración, cabe preguntar por las condiciones de posibilidad, a través de las cuales, la evaluación mediante de un conjunto casi infinito de mecanismos - de discursos y de prácticas- ha cobrado tal relevancia social, que en la actualidad la caracteriza.

En tal cultura de la omnievaluación y al interior de los sistemas educativos, todas las instancias, los ámbitos, las instituciones, los sujetos, los conocimientos, los

${ }^{*}$ DOI - 10.29388/978-65-86678-87-1-0.f.68-82 
procesos, las acciones, los proyectos, los programas, en fin, las palabras, las cosas, son sometidos a una pluralidad de procedimientos evaluativos que comportan una variedad de instrumentos, tiempos, espacios..., en orden, también a una pluralidad de usos y fines. Esta trama de discursos y prácticas permiten sostener que la evaluación se ha convertido en un dispositivo que yace presente en la cotidianidad educativa y que tiene implicaciones -de enorme calado- para todos los estamentos y elementos relativos y correlativos al ejercicio docente.

La analítica que devela este artículo, es resultante del uso de la caja de herramientas de raigambre foucaultiano, arqueológico, genealógico y de subjetividad. Es un ejercicio arqueológico, pues, busca describir lo efectivamente dicho (escrito, enunciado, nombrado...) acerca de la evaluación a través de un archivo documental conformado por diversos corpus (teóricos, metateóricos, prescriptivos, práxicos...) que refieren de múltiples maneras a la evaluación docente; es genealógico porque busca determinar -y señalar- las condiciones de posibilidad a través de las cuales la práctica evaluativa se ha constituido en una especie de juez omnipoderoso, omnipotente, al que todo ha de ser sometido; se refiere, finalmente, a una perspectiva de subjetividad, por cuanto la evaluación, al realizar el ejercicio de control docente, constituye o produce un tipo específico de sujeto: perpetuamente vigilado, controlado, evaluado, valorado.

Este ejercicio académico-investigativo se deriva de la conjugación de dos elementos básicos: el trabajo de investigación doctoral "Aproximación a un estudio genealógico de la evaluación educativa en Colombia, segunda mitad del siglo XX" (Sánchez, 2008) y la propuesta de investigación "La evaluación: un proceso de formación y transformación docente" (Sánchez, De la Torre y Mosquera, 2016).

\section{Método de la propuesta (Arqueología-Genealogía-Subjetividad)}

Este ejercicio investigativo constituye una analítica -descriptiva e interpretativa- de la verdad, referida a la evaluación como mecanismo de control del trabajo docente, que se fundamenta en tres herramientas metodológicas:

[...] un rastreo arqueológico, con el objeto de describir las condiciones históricas de posibilidad del saber; un análisis genealógico de las formas de poder, puesto en funcionamiento a través de las prácticas, para "mostrar las piezas que lo articulan y su mecánica"; y, una analítica interpretativa (Dreyfus y Rabinow, 2001), a fin de develar su maniobra como técnica para el agenciamiento de sujetos (Sánchez, 2009, p. 1680).

\subsection{Descripción arqueológica}

La arqueológica, en tanto herramienta metodológica constituye "una historia de las condiciones históricas de posibilidad del saber" (Castro, 2004, p. 32); es un método de análisis de discursos y de prácticas que indaga las reglas generales de las 
relaciones entre los enunciados, a través de los cuales se puede configurar un saber determinado - para este caso, la evaluación-, en una época dada. Es una analítica de los saberes institucionalizados (Zuluaga, 1987), que describe las reglas que para los sujetos, las instituciones, los discursos de un saber específico, "delimitan la práctica del mismo saber en una formación social dada" (p. 28).

La descripción arqueológica comenzó determinando las fuentes documentales (discursivas y no discursivas), esto es, conformando el archivo sobre el cual se operaría el análisis; luego, se realizó el registro de algunas modalidades enunciativas referidas a la evaluación que se hallaron dispersas en el corpus documental; finalmente, a través de una analítica interpretativa se procedió a la sistematización de las formas de evaluación que operan como mecanismos de control del trabajo docente.

\subsection{Perspectiva genealógica}

Esta perspectiva permite el análisis -interpretativo- sobre las redes de relaciones, poderes y fuerzas que se operan en y desde el objeto evaluación. La genealogía permite "establecer el espacio de emergencia, el momento en que surge, o la procedencia de una institución, un concepto, una práctica o un discurso" (Morey, 1983, p. 238).

Por la mediación genealógica fue posible percibir la singularidad y la particularidad de las prácticas evaluativas, de los discursos que circulan, de las relaciones que se traman entre discurso y prácticas y que implican dominaciones o sumisiones. La dimensión genealógica de este ejercicio permitió evidenciar "escenarios donde innumerables luchas miden su fuerza, para producir destellos que, como acontecimientos, auguran la emergencia de un saber, de un objeto, de un concepto, de una práctica, de un discurso" (Sánchez, 2009, p. 1681). La genealogía, pues, se ocupó de asistir a la emergencia del evento evaluativo y de analizar las relaciones que en torno suyo se traman y los modos como esta maquinaria controla, vigila, regulariza, normaliza... la labor docente.

\subsection{Instancia de la subjetividad}

Este ejercicio comporta finalmente, una ontología histórica del presente: ontología, en tanto pregunta por unos sujetos que son confinados a procedimientos evaluativos perpetuos; histórica, por cuanto, manifiesta la preocupación por un tiempo en el que se juega la existencia individual, esto es un aquí y un ahora. La indagación, desde esta perspectiva ontológica, da cuenta entonces, de cómo los sujetos (docentes) son compelidos, atravesados, seriados..., agenciados, en fin, por diversos dispositivos de una gran maquinaria evaluativa y examinatoria.

Una analítica de la subjetividad permite confrontar a los individuos con la historia de su propio presente y con las formas como pueden ir transitando diversos trayectos (de la sujeción a otros a la auto- 
sujeción, del paso de una instancia disciplinaria a otra, de un rol determinado a otro, del tránsito de una sociedad de disciplinamiento a otra de control). (Sánchez, 2009, p. 1681).

\section{Descripción y Análisis. Evaluación: dispositivo de control del trabajo docente}

Este apartado se ocupa de la descripción y el análisis de diversas formas o modalidades de evaluación que son puestas en funcionamiento sobe el trabajo docente y que fungen como dispositivos de control; para ello se acude, al análisis de una masa documental constituida por diversas normas nacionales (leyes y decretos sobre educación superior) y las reglamentaciones, que en materia de evaluación docente, regulan las relaciones entre las instituciones de Educación superior en Colombia y sus docentes.

Anclo los linderos temporales del análisis en los primeros años de la década de los 90, con la expedición de las reformas más importantes que en materia de educación: Ley 30 de 1992 (Congreso de Colombia, 1992) y Ley General de Educación (Congreso de Colombia, 1994), respectivamente; y, hago un recorrido analítico por diversas normativas nacionales e institucionales que dan cuenta de la puesta en funcionamiento de los discursos y las prácticas evaluativas, como mecanismos de control de la labor docente.

La Ley General de Educación instaura la cultura de la evaluación a través del Sistema Nacional de Evaluación de la Educación, "con el fin de velar por la calidad, por el cumplimiento de los fines de la educación y por la mejor formación moral, intelectual y física de los educandos"; tal sistema, ordena la Norma, deberá operar en coordinación con "el Servicio Nacional de Pruebas del Instituto Colombiano para el Fomento de la Educación Superior, ICFES, y con las entidades territoriales" y, se constituirá en la base "para el establecimiento de programas de mejoramiento del servicio público educativo" (Art. 80). Este sistema:

[...] diseñará y aplicará criterios y procedimientos para evaluar la calidad de la enseñanza que se imparte, el desempeño profesional del docente y de los docentes directivos, los logros de los alumnos, la eficacia de los métodos pedagógicos, de los textos y materiales empleados, la organización administrativa y física de las instituciones educativas y la eficiencia de la prestación del servicio.

La ley estatutaria de la Educación Superior en Colombia (Congreso de Colombia, 1992) es parca en señalar procedimientos evaluativos para los docentes de este nivel de educación; esta normativa se limita a enunciar que: la inspección y vigilancia de la Educación Superior debe propender por "la creación de mecanismos de evaluación de la calidad de los programas académicos" (Art. 31); mediante el "desarrollo de un proceso de evaluación que apoye, fomente y dignifique la Educación Superior" (Art. 32); que permita estimular y perfeccionar procedimientos 
de autoevaluación (Art. 38); y, fomente la autoevaluación como tarea institucional permanente (Art. 55). Específicamente, en lo relativo a la evaluación docente, la norma ordena que los estatutos profesorales de cada universidad establezcan "un sistema de evaluación del desempeño del profesor universitario" (Art. 75); y, que contemplen "Requisitos de vinculación, sistemas de evaluación y capacitación, categorías, derechos y deberes, distinciones e incentivos y régimen disciplinario" (Art. 123).

Para ser profesor de una universidad estatal u oficial se exige "poseer título profesional universitario"; la incorporación y nombramiento "se efectuará previo concurso público de méritos cuya reglamentación corresponde al Consejo Superior Universitario" (Art. 70).

En virtud de lo establecido por la ley, a diferencia de lo que acontece con la educación básica, en la superior no existe un estatuto docente unificado, la norma delega a las universidades, dada su autonomía, la expedición de sus propios reglamentos; en consecuencia, cada institución es responsable de los regímenes docentes en los cuales se plasman las acciones las interacciones y las relaciones docentes-instituciones. No obstante para tratar de subsanar las falencias que en materia evaluativa presenta la ley estatutaria de la Educación Superior, el gobierno expide el Decreto 1279 de 2002 (Presidencia de la República. Ministerio de Educación Nacional, 2002), por el cual se establece el régimen salarial y prestacional de los docentes de las Universidades Estatales que, si bien no constituye un estatuto docente, en cuanto tal, determina el régimen salarial de los docentes, cuya base y presupuesto lo constituyen una pluralidad de procedimientos evaluativos que permean la totalidad de las funciones y labores de los docentes de la Educación Superior.

El capítulo 2 de esta norma se refiere a "la asignación de puntos para la remuneración inicial de los docentes que ingresan por primera vez o reingresan a la carrera docente, o para los que proceden de otro régimen", allí se pueden develar prácticas $-y$ discursos- evaluativos que están estrechamente relacionadas con factores económicos y administrativos que determinan las asignaciones salariales de los docentes, según una puntuación determinada, que generalmente es responsabilidad de un Comité de Asignación de Puntaje y Escalafonamiento. "Los puntajes se establecen de acuerdo con la valoración de los siguientes factores: a) Los títulos correspondientes a estudios universitarios; b) La categoría dentro del escalafón docente; c) La experiencia calificada; d) La productividad académica". (Art. 6). El Decreto (Art. 8), determina cuatro categorías en el escalafón docente cuya puntuación se asigna así: a) Instructor o Profesor Auxiliar, o Instructor Asistente, treinta y siete (37) puntos; b) Profesor Asistente, cincuenta y ocho (58) puntos; c) Profesor Asociado, setenta y cuatro (74) puntos; d) Profesor Titular, noventa y seis (96) puntos (Art. 8).

La experiencia (anual) calificada se valora (y puntúa) de la siguiente manera: investigación, en cualquier campo de la ciencia, la técnica, las humanidades, el arte o la pedagogía, hasta seis (6) puntos; experiencia docente universitaria, hasta cuatro (4) puntos; experiencia profesional calificada en cargos de dirección académica hasta 
cuatro (4) puntos; experiencia profesional calificada diferente a la docente, hasta tres (3) puntos. (Art. 9).

Toda actividad reflejada en productividad académica (artículos, ensayos, comunicaciones cortas, producción de videos, cinematografías, fonografías, libros (de texto, ensayos), premios y menciones, patentes, traducciones, obras artísticas, obras de creación complementaria, producción técnica, producción de software...) es sometida a la valoración por parte de pares académicos y se puntuará según los siguientes criterios:

- $\quad$ Artículos. En revistas tipo Al, quince (15) puntos; en revistas tipo A2, doce (12) puntos; en revistas del tipo $B$, ocho (8) puntos; en revistas tipo $C$, tres (3) puntos; Comunicaciones cortas, el $60 \%$ del puntaje que le corresponde según su nivel y clasificación.

- $\quad$ Producción de videos, cinematografías o fonografías. De difusión e impacto internacional, doce (12) puntos; de impacto y difusión nacional, siete (7) puntos.

- Libros. Resultantes de investigación, hasta veinte (20) puntos; libros de texto y ensayos, hasta quince (15) puntos.

- $\quad$ Premios nacionales e internacionales, hasta quince (15) puntos.

- Patentes, hasta veinticinco (25) puntos.

- $\quad$ Traducciones de libros, hasta quince (15) puntos.

- Obras de creación original artística: de impacto o trascendencia internacional, hasta veinte (20) puntos; de impacto o trascendencia nacional, hasta catorce (14) puntos.

- Obras de creación complementaria o de apoyo: de impacto o trascendencia internacional, doce (12) puntos; de impacto o trascendencia nacional, ocho (8) puntos.

- Interpretación: de impacto o trascendencia internacional, hasta catorce (14) puntos; de impacto o trascendencia nacional, hasta ocho (8) puntos.

- $\quad$ Producción técnica: diseño de sistemas o procesos que constituyen una innovación tecnológica y que tienen impacto y aplicación, hasta quince (15) puntos; diseño de sistemas o procesos que constituyen una adaptación tecnológica y que tienen impacto y aplicación, hasta ocho (8) puntos.

- $\quad$ Producción de Software, hasta quince (15) puntos (Art. 10).

La norma ordena a los Consejos Superiores universitarios la reglamentación del proceso de selección de los pares externos evaluadores (de la lista de Colciencias), para la evaluación de la productividad, de modo que se asignen por lo menos dos (2) evaluadores para cada producto; demanda, además, que los evaluadores sean rotativos de diferentes universidades, de modo que se evite "la repetición de un mismo evaluador, o de un grupo restringido de ellos, por parte de la misma universidad en procesos de evaluación consecutivos". El Decreto fija, unos topes máximos de reconocimiento de puntos salariales por productividad según categorías, 
así: Profesor Auxiliar: 80 puntos; Profesor Asistente: 160 puntos; Profesor Asociado: 320 puntos; Profesor Titular: 540 puntos; Instructor Asociado: 110 puntos. (Art. 10).

Una vez inscritos en el escalafón, los docentes pueden modificar sus puntos salariales por los siguientes factores: títulos correspondientes a estudios universitarios de pregrado o posgrado; categoría dentro del escalafón docente; productividad académica; actividades de dirección académico-administrativas; desempeño destacado en las labores de docencia y extensión; Experiencia calificada. En todo caso las puntuaciones asignadas corresponden a lo ya referido respecto de la productividad académica. Por otra parte, señala la norma: "para evaluar, analizar y asignar puntos a la productividad académica (...), todas las universidades estatales $u$ oficiales deben adoptar un sistema de Evaluación Periódica de Productividad" (Art. 16).

Las actividades de dirección académica-administrativa son, de igual manera, valoradas y puntuadas según los encargos realizados, así: Rector, hasta once (11) puntos; Vicerrectores, Secretario General y Director Administrativo General, hasta nueve (9) puntos; Decanos, directores o jefes de división, jefes de oficina, Directores de oficinas de investigación, extensión o de programas curriculares, hasta seis (6) puntos; Vicedecanos y Directores administrativos de Sede o Seccional, hasta cuatro (4) puntos; Directores de Departamentos, Escuelas, Institutos, Centros u otras unidades de gestión académico-administrativa en las Facultades hasta dos (2) puntos (Art. 17).

El excelente desempeño académico de los profesores en actividades de docencia, investigación y proyección es reconocido y valorado, anualmente, a través de mecanismos de evaluación determinados por los Consejos Superiores Universitarios, dicho reconocimiento es conducente a la asignación de puntos salariales y de bonificación, según la categoría del escalafón: Profesor Titular Hasta 5 puntos; Profesor Asociado Hasta 4 puntos; Profesor Asistente Hasta 3 puntos; Profesor Auxiliar e Instructor Asociado Hasta 2 puntos (Art. 18).

A los docentes en ejercicio se reconocen bonificaciones (por una única vez y, no constitutivas en salario) por productividad académica, según los criterios que los Consejos Superiores pueden establecer; dichas bonificaciones se otorgan sobre los siguientes productos: Producción de videos, cinematográficas o fonográficas; Obras Artísticas; Ponencias en eventos especializados; Publicaciones impresas universitarias; Estudios posdoctorales; Reseñas críticas; Traducciones; Direcciones de tesis; Evaluación como par. (Art. 20).

Las universidades, en cumplimiento de lo ordenado por los Artículos 23 y 24 de este Decreto, pueden (deben) reconocer a los docentes, puntos salariales a los siguientes productos: Publicaciones en revistas que no estén clasificadas, indexadas u homologadas por Colciencias; Producción de videos, cinematográficas o fonográficas; Libros derivados de investigación, de texto y ensayos; Traducción de libros; Premios nacionales e internacionales; Patentes; Obras artísticas; Producción técnica; Producción de software.

En todos los casos (asignación de puntos salariales o de bonificación) el Comité Interno de Asignación y Reconocimiento de Puntaje o el organismo creado por las 
universidades para tal efecto, realiza la valoración teniendo en consideración los siguientes criterios: “a) Calidad académica, científica, técnica, humanística, artística o pedagógica; b) Relevancia y pertinencia de los trabajos con las políticas académicas; c) Contribución al desarrollo y cumplimiento de los objetivos institucionales definidos en las políticas de la universidad." (Art. 26).

La conclusión derivada de esta lectura analítica del decreto que reglamenta el régimen salarial y prestacional de los docentes de las Universidades Estatales es, que todas las acciones, todas las labores, toda la productividad... de los docentes, es sometida a ingentes procedimientos de valoración, de vigilancia y control, en todo momento, por diferentes sujetos, colegiados e instancias. En pocas palabras, toda la vida académica y extra académica de los docentes está cifrada, atravesada, marcada, por diversos procedimientos de evaluación que, como señala Foucault, hacen de cada individuo un caso (Vigilar y castigar, 1976): un caso para la vigilancia, un caso para el control.

En consonancia con las normas referidas $y$, en perspectiva de dar cumplimiento a lo ordenado por la Ley Estatutaria de la Educación Superior, el Consejo Superior de la Universidad Distrital expidió el Estatuto del Docente de Carrera (Universidad Distrital Francisco José de Caldas. Consejo Superior Universitario, 2002), norma que determina los procesos evaluativos que se ciernen sobre los docentes.

La normativa contempla como elementos valorativos de la acción del cuerpo profesoral: la generación de "espacios académicos para garantizar una gestión docente" que propenda "la búsqueda permanente del mejoramiento de la calidad y la excelencia", la definición de las condiciones para "el desempeño de las actividades académicas y administrativas del docente, las categorías del escalafón docente y los criterios para la evaluación de las actividades docentes"; la garantía de la estabilidad laboral de los docentes, que se deriva de "los méritos, la productividad académica y la evaluación del desempeño"; la definición de "las condiciones y procedimientos para la inscripción, evaluación, ascenso y retiro de los docentes de carrera en la Universidad..." (Art. 2).

La definición de Docente (Art. 4) implica caracterizaciones relativas al ejercicio de evaluación, pues, para ser vinculado a la institución, en cualquiera de las modalidades de docencia (carrera o vinculación especial), se debió surtir un "concurso publico de meritos (sic)" $y$, las funciones que debe desempeñar (enseñanza, comunicación, investigación, innovación o extensión: en la ciencia, la pedagogía, el arte, la tecnología, en fin, todas las formas del saber $y$, la cultura), tienen como correlato diversos procedimientos valorativos.

La acreditación de título profesional "expedido por una universidad colombiana legalmente reconocida o título otorgado en el exterior y convalidado en Colombia" o, la exención de aquel, por "haber realizado aportes significativos en uno o varios campos del saber, la técnica, el arte o las humanidades en calidad de docentes expertos", constituyen de facto, a criterio del Consejo Superior Universitario, mecanismos de selección (ponderación) para el ejercicio magisterial.

Además de ser objeto de evaluación sobre el que recae una pluralidad de formas examinatorias y valorativas, el docente es sujeto de la evaluación, pues dentro 
de sus deberes se cuentan (Art. 20, literales k, i) la obligatoriedad de: "realizar las evaluaciones académicas programadas y publicar las calificaciones de las pruebas intermedias y finales en los términos reglamentarios"; $y$, de "entregar al Coordinador del Proyecto Curricular las notas definitivas de los cursos a su cargo en la fecha señalada por la universidad". La evaluación se ha constituido, en un deber connatural, obligatorio, ineludible... de la labor docente.

Los principios y fundamentos de la carrera docente están signados por sutiles concepciones valorativas, así, por ejemplo: garantía de la "excelencia académica de la Universidad", fomento a la "actualización permanente", regulación de las "condiciones de inscripción, ascenso y retiro", "evaluación del desempeño". (Arts. 2122).

El Escalafón Docente, señala el Estatuto, es el "sistema de clasificación" de los docentes de carrera que se realiza a partir de los siguientes elementos: títulos universitarios, producción académica, experiencia universitaria calificada (adquirida en actividades propias como docente universitario), experiencia profesional calificada y, categoría dentro del escalafón docente (Art. 24). Dicho sistema de clasificación docente contempla cuatro categorías: Auxiliar, Asistente, Asociado y Titular (Art. 25). La superación (aprobación) del periodo de prueba es requisito sine que non para la inscripción en alguna categoría del escalafón.

Para el ascenso a cualquiera de las categorías determinadas por las normas, se demanda, además de los títulos de pregrado y posgrado requeridos: una temporalidad mínima de permanencia; la elaboración y sustentación, ante jurado, de un trabajo que constituya un aporte significativo "al área o disciplina académica en que se desempeñe o concurse"; $y$, obtener los resultados de la evaluación docente "como mínimo en el rango de aceptable" (Arts. 26-29).

La normativa contempla un concepto denominado estabilidad (el derecho del docente a permanecer en el cargo y en la categoría) "siempre y cuando no haya llegado a la edad de retiro forzoso, observe buena conducta y obtenga una evaluación aceptable de su desempeño" (Art. 34). Los periodos de estabilidad son de tres (3), cuatro (4), cinco (5) y seis (6) años según las categorías señaladas. Todo profesor que gana concurso en la institución ingresa en período de prueba, de un (1) año, a cuyo término "previa evaluación global en la que obtenga como mínimo el rango de aceptable, se inscribe al docente en el escalafón" (Art. 36).

La Universidad Distrital cuenta con un "Comité de Personal Docente y de Asignación de Puntaje", organismo facultado para tomar decisiones sobre "la inscripción y ascenso en el escalafón" (Art. 44). En general, las funciones de este comité son valorativas, pues, le compete:

a) Determinar los puntajes correspondientes a los factores (...).

b) Realizar la actividad de valoración y asignación de puntaje (...).

d) Asesorar al Rector, al Consejo Académico y al Vicerrector, en todo lo relacionado con el diseño de políticas para la formación, actualización y evaluación del personal docente de la Universidad (Art. 46). 
El estatuto docente (Art. 54), en cumplimiento de lo ordenado por la Ley 30 de 1992, contempla lo relativo a la evaluación docente, que es conceptualizada como:

[...] el proceso permanente y sistemático mediante el cual se analiza, valora y pondera la gestión del docente en la Universidad. Es un componente del proceso de evaluación institucional cuyo fin es mejorar la calidad de la gestión académica, en búsqueda de la excelencia. Permite a la Universidad acopiar información valiosa con miras a su acreditación permanente ante las comunidades académicas especializadas y ante la sociedad civil en general.

Los objetivos de la evaluación de docentes se orientan hacia "el mejoramiento académico de la Universidad y el desarrollo profesional de los docentes"; en consecuencia, sus resultados "deben servir de base para la formulación de políticas, planes y programas de desarrollo académico y de capacitación del docente, así como para la inscripción, ascenso y retiro del escalafón y para la renovación de los periodos de estabilidad" (Art. 55). Los procesos de evaluación (heteroevaluación, por parte de los estudiantes; coevaluación, realizada por los superiores y/o jefes inmediatos; y, autoevaluación, ejercicio de valoración de uno consigo mismo), concurren cada semestre "después de finalizada la octava semana de clases"; y son responsabilidad del Consejo de Facultad (Art. 55).

Además del Comité de Personal Docente y de Asignación de Puntaje, la Universidad cuenta con un Comité de Evaluación cuyas funciones son eminentemente valorativas (Art. 58):

Planear, socializar, diseñar y actualizar las políticas de evaluación docente en la Universidad Distrital.

Definir metodologías y procedimientos para la aplicación, recopilación, tabulación y análisis de la información de la evaluación docente.

Liderar los procesos de sensibilización y socialización del proceso de evaluación docente.

Definir la reglamentación para incentivar la práctica docente y fijar las medidas y correctivos pertinentes para los distintos resultados de la evaluación.

Los procedimientos de la evaluación de docentes -o de docentes con cargos de dirección- en la Universidad Distrital se realizan teniendo en consideración los siguientes elementos, (Art. 61-64):

- $\quad$ Protagonistas (quienes evalúan): alumnos, docentes y consejos curriculares;

- $\quad$ Categorías y unidades de análisis (lo que se evalúa de los docentes): práctica docente, actitudes frente a la actividad docente, compromisos institucionales, conocimientos, investigación y extensión, capacitación y 
publicaciones, preparación de actividades, dirección de actividades de los alumnos en clase, evaluación de las asignaturas que orienta, motivación hacia el conocimiento, relaciones interpersonales, cumplimiento de las actividades docentes, conocimientos sobre las asignaturas que se enseñan, conocimientos pedagógicos o didácticos de las asignaturas, formulación y desarrollo de proyectos de investigación y/o extensión, creación de escuelas de pensamiento, conformación de grupos de investigación, relación docencia-investigación, impacto de proyectos de investigación y/o extensión, cumplimiento de funciones académico administrativas, desarrollo de actividades de publicación y capacitación;

- Indicadores (instrumentos, encuestas institucionales normalizadas): preguntas realizadas a los protagonistas de la evaluación docente...;

- $\quad$ Escalas de calificación (rengos de valoración): cualitativa y cuantitativa (...). Excelente (5), Bien (4) Aceptable (3), Regular (2), Deficiente (1); Siempre (5), Frecuentemente (4), Ocasionalmente (3), Rara Vez (2), Nunca (1); Lo realiza (5) Lo Realiza Parcialmente (3). No lo Realiza (1);

- $\quad$ Criterios de ponderación (porcentajes de la evaluación): consejo del proyecto (30\%); estudiantes (50\%) autoevaluación del profesor (20\%);

- $\quad$ Otros criterios que, en el marco de un espíritu constructivo, orientado al desarrollo profesional y pedagógico del docente, implican la evaluación: solvencia académica, metodología de trabajo y, cumplimiento de su gestión universitaria;

- $\quad$ Temporalidad: una vez por semestre, al término de la octava semana de clase.

- Cuantificación: expresada en puntos, resultante de la ponderación según los resultados obtenidos, así: excelencia académica, satisfactoria, bien, aceptable, deficiente.

La evaluación aporta información suficiente para la toma de decisiones en los órdenes de la promoción (reconocimiento) o punición (castigo); determina la ubicación de los docentes en estado de aprobación (si se obtiene la categoría de aceptable); o, en "periodo de prueba" (si se obtiene deficiente). En este último caso, el docente "deberá tomar cursos de capacitación y actualización con el fin de corregir las deficiencias que haya arrojado el proceso de evaluación". Al cabo del periodo de prueba se debe obtener una cualificación aceptable, de lo contrario, el docente es removido del servicio mediante Resolución Motivada (Art. 65).

El Estatuto en análisis, contempla también la Meta evaluación, por cuanto deja abierta las posibilidades para los recursos facultados en derecho, (Art. 66):

Ante los resultados del proceso de Evaluación Docente, el profesor podrá interponer recursos de reposición ante el Comité de Evaluación Docente de la Facultad y en subsidio de apelación ante el Consejo de la respectiva Facultad. En caso de encontrar méritos, éste puede ordenar la revisión de la evaluación y decide en última instancia en los términos de ley. 
La norma, en consonancia con el señalado Decreto 1279 de 2002, instaura un "sistema de evaluación periódica de productividad" que se ordena a "bonificar las actividades de docencia, investigación y extensión y, en particular, para estimular la participación de los docentes en las diferentes modalidades de la actividad docente" (Art. 70). El reconocimiento de los puntos salariales por producción académica, según la evaluación efectuada por los pares externos, es responsabilidad del Comité de Personal Docente y Asignación de Puntaje (Art. 72).

Adicional al reconocimiento de la excelencia académica, los procedimientos evaluativos arrojan información conducente al establecimiento de diversas distinciones académicas, así: Docente investigador, Docente emérito, Docente honorario, Maestro universitario (Art. 75-79), teniendo en consideración el tiempo de permanencia y servicio en la institución y de aportes al conocimiento. El procedimiento a través del cual se conceden estos estímulos, constituye, a todas luces una práctica evaluativa, toda vez que "El Consejo Superior Universitario, a propuesta del rector y previo concepto favorable del Consejo Académico, otorga las distinciones"; que son entregadas en sesiones solemnes especiales. Como la titulación al término de un curriculum (carrera), la ceremonia de reconocimiento y la entrega de los diplomas, constituyen las más elevadas formas de valoración, como exaltación y reconocimiento de méritos por la labor cumplida.

En materia de evaluación, finalmente, el Estatuto Docente afirma que la Institución fomenta programas de formación (permanente y avanzada) que contribuyen al reconocimiento del mérito de los docentes: "Al efecto otorga comisiones, becas y otros incentivos" (Art. 82). De igual manera, los docentes de carrera -de tiempo completo- tienen la posibilidad de gozar "cada siete (7) años, de un año remunerado que se denomina año sabático" (Art. 83). Una evaluación de excelencia académica es factor determinante para el logro de estos beneficios.

Para ir cerrando este acápite, quiero referirme a modo de mención solamente -en perspectiva de dejar abierta la posibilidad a próximos análisis- a otra normativa institucional (Universidad Distrital Francisco José de Caldas. Consejo Superior Unoversitario, 2007) que devela un significativo conjunto de prácticas evaluativas (vigilancia, agenciamiento, gestión, control) que se operan sobre el ejercicio docente, o sobre las condiciones para su posibilidad; se trata del "Reglamento de Concurso Público de Méritos para la provisión de cargos en la Planta de Personal Docente".

Esta norma describe $-y$ prescribe- una pluralidad de procedimientos evaluativos y examinatorios (rigurosos, meticulosos, cuidadosos, finos...), para los docentes que pretenden participar del Concurso Público de Méritos en orden a vincularse a la Planta de la Universidad.

Como su nombre lo indica, el concurso (sus etapas, procedimientos y acciones) implica un conjunto mayúsculo de prácticas evaluativas: el objeto, la definición, la verificación de la existencia de las vacantes, la determinación de los perfiles, la publicación de las convocatorias, el registro de documentos, la determinación de las modalidades de concursos, la declaración de cumplimiento de los perfiles o de los concursos desiertos, la selección de jurados (idoneidad, funciones, inhabilidades), la determinación de factores de evaluación de los concursos (competencias 
profesionales y comunicativas -valoración de las pruebas oral y escrita-, hoja de vida -experiencia, títulos, investigación o creación, publicaciones, segunda lengua-, desempeños académicos para jóvenes talentos), la publicación de resultados de las pruebas, los procedimientos para el desarrollo de los concursos, la publicación de resultados finales, la atención a vías gubernativas, el nombramiento, la evaluación periodo de prueba-, el nombramiento en propiedad, la determinación de los criterios para retiro (renuncia, declaración de insubsistencia, destitución, invalidez absoluta, nulidad del nombramiento, orden judicial o muerte del docente).

Todo lo descrito me permite colegir que, desde el inicio hasta el fin de la vida, toda la existencia de los seres humanos, se halla atada a múltiples valoraciones, valoraciones que se multiplican de mil modos si esa vida se ocupa del ejercicio de la docencia en cualquiera de los órdenes o niveles de la educación.

\section{A modo de colofón}

La evaluación se ha instalado de manera prodigiosa en la acción educativa y, en ella, opera de mil modos sobre la labor docente. Un análisis operado sobre diversas piezas documentales que prescriben normativas acerca de la evaluación docente muestra como ésta se ha convertido en una red casi infinita que, a través de diversos procedimientos de regulación, de vigilancia, de disciplina..., controla absolutamente todo el quehacer docente, en todo momento, en todo lugar, en todos los ámbitos.

Sostengo que la evaluación se ha convertido en una pieza connatural a la labor docente -y dicente- podría decir, glosando a García Márquez, que los seres humanos, pero más los docentes, son evaluados "desde la cuna hasta la tumba" (García Márquez, 1994). El ingreso a una institución, su permanencia, su egreso; primeo como dicentes, luego como docentes, está cifrado por un incontable número de prácticas evaluativas, que de múltiples maneras logran conducirle a la promoción, al reconocimiento, a la valoración o, a la exclusión. La evaluación se ha convertido, en el juez natural, ineludible, necesario del desempeño docente.

Al docente y/o al directivo docente se le evalúa todo y por todo (lo que hace y lo que deja de hacer); en todo lugar (dentro y fuera de la escuela); en todo tiempo (cada periodo académico, cada semestre, cada año, permanente, continuamente); de múltiples maneras (a través de diferentes formatos e instrumentos); es evaluado por todos (jefes, directivos, administrativos, colegas, estudiantes, padres de familia, autoridades educativas...). Sobre ellos, los docentes, se cifra -de mil modos- la evaluación, a la manera de un panóptico generalizado que todo lo vigila, que todo lo controla, que todo lo somete.

Con independencia del nivel, forma, modalidad o instancia educativa en el que se desempeñe el docente, las prácticas evaluativas recaen sobre la totalidad de sus acciones: dominio de estrategias y habilidades pedagógicas y de evaluación; manejo de la didáctica propia del área o nivel educativo de desempeño; habilidades en resolución de problemas; nivel de conocimiento y habilidades relacionadas con el plan 
de estudios de la institución; actitudes generales hacia los alumnos; manejo de las relaciones del grupo; trato y manejo de la disciplina de los alumnos; sentido de compromiso institucional; preocupación permanente por el mejoramiento de la calidad de la educación; logro de resultados; práctica docente; actitudes frente a la actividad docente; compromisos institucionales; conocimientos; investigación y extensión; capacitación y publicaciones; preparación de actividades; dirección de actividades de los alumnos en clase; evaluación de las asignaturas que orienta; motivación hacia el conocimiento; relaciones interpersonales; cumplimiento de las actividades docentes; conocimientos sobre las asignaturas que se enseñan; conocimientos pedagógicos o didácticos de las asignaturas; formulación y desarrollo de proyectos de investigación y/o extensión; creación de escuelas de pensamiento; conformación de grupos de investigación; relación docencia-investigación; impacto de proyectos de investigación y/o extensión; cumplimiento de funciones académico administrativas; desarrollo de actividades de publicación y capacitación.

En todas esas instancias, en fin, la evaluación opera como mecanismo de control, incluso, como dispositivo de producción no solo de sujetos, sino también de objetos, de instituciones, de programas, de procesos. La evaluación, en las actuales las sociedades de control, se ha convertido en el nuevo emperador de los sujetos, de los objetos, de las palabras, de las cosas.

\section{Referencias}

LBANO, S. Michel Foucault. Glosario epistemológico. Buenos Aires: Quadrata. 2006

CASTRO, E. El vocabulario de Michel Foucault. Buenos Aires: Prometeo-Universidad Nacional de Quilmas, 2004

Congreso de Colombia. Ley 30 de 1992. Por el cual (sic) se organiza el servicio público de la Educación Superior, 1992. Recuperado a partir de: https://www.cna.gov.co/1741/articles-186370_ley_3092.pdf

Congreso de Colombia. Ley 115 de 1994. Por la cual se expide la ley general de educación, 1994. Recuperado 21 de agosto de 2017, a partir de http://www.secretariasenado.gov.co/senado/basedoc/ley_0115_1994.html

DREYFUS, H. y RABINOW, P. Michel Foucault: más allá del estructuralismo y la hermenéutica. Buenos Aires: Nueva Visión SAIC, 2001. Recuperado a partir de https://www.casadellibro.com/libro-michel-foucault-mas-alla-del-estructuralismo-yla-hermeneutica/9789506024338/827755

GARCÍA MÁRQUEZ, G. Por un país al alcance de los niños. El Espectador. Sección General, p. 12-A, 1994. Recuperado a partir de https://scp.com.co/ArchivosSCP/Por_un_pais.pdf

MOREY, M. Lectura de Foucault. Madrid: Taurus. 1983 
Presidencia de la República. Ministerio de Educación Nacional. Decreto 1279 de 2002. Por el cual se establece el régimen salarial y prestacional de los docentes de las Universidades Estatales. Colombia, 2002.. Recuperado a partir de http://www.mineducacion.gov.co/1621/articles-86434_Archivo_pdf.pdf

SÁNCHEZ, T., De la Torre. O. y Mosquera, F. Propuesta de investigación. La evaluación: un proceso de formación y transformación docente. 2016. Bogotá: No publicado.

SÁNCHEZ, T. Aproximación a un estudio genealógico de la evaluación educativa en Colombia, segunda mitad del siglo XX. Universidad de Manizales-Cinde, 2008.

Recuperado a partir de http://biblioteca.clacso.edu.ar/Colombia/alianza-cinde-umz/20091210042624/tesissanchez.pdf

SÁNCHEZ, T. Aproximación a un estudio genealógico de la evaluación en Colombia, siglo XX. Revista Latinoamericana de Ciencias Sociales, Niñez y Juventud, v. 7(, n. 2, p. 1675-1711, 2009. Recuperado a partir de http://www.umanizales.edu.co/revistacinde/index.htmlAproximaciónaunestudiogene alógicodelaevaluaciónenColombia,

SÁNCHEZ, T. La evaluación educativa como dispositivo de constitución de sujetos.

Revista Latinoamericana de Ciencias Sociales, v. 11, n. 2, p. 755-767, 2013. Recuperado a partir de http://revistalatinoamericanaumanizales.cinde.org.co/? page_id $=2271$

Universidad Distrital Francisco José de Caldas. Consejo Superior Universitario. Estatuto del profesor. Acuerdo No. 011 de 2002. Por el cual se expide el Estatuto del Docente de carrera de la Universidad Distrital Francisco José de Caldas", 2002. Recuperado 21 de agosto de 2017, a partir de http://sgral.udistrital.edu.co/xdata/csu/acu_2002-011.pdf

Universidad Distrital Francisco José de Caldas. Consejo Superior Unoversitario. Acuerdo 005 de 2007. Por el cual se expide el Reglamento de Concursos Públicos de Méritos para la provisión de cargos en la Planta de Personal Docente de la Universidad Distrital Francisco José de Caldas, 2007. Recuperado 21 de agosto de 2017, a partir de http://sgral.udistrital.edu.co/xdata/csu/acu_2007-005.pdf

Universidad Distrital, \& Francisco José De Caldas. Oficina de Docencia. Formato No. 7- Evaluación de docentes por estudiantes, 2010. Recuperado 22 de septiembre de 2017, a partir de http://www1.udistrital.edu.co:8080/documents/62257/edf42c77452b-4881-a0d2-216504cbeef2

ZULUAGA, O. Pedagogía e historia. La historicidad de la pedagogía. La enseñanza, un objeto de saber. Bogotá: Foro Nacional por Colombia, 1987. 